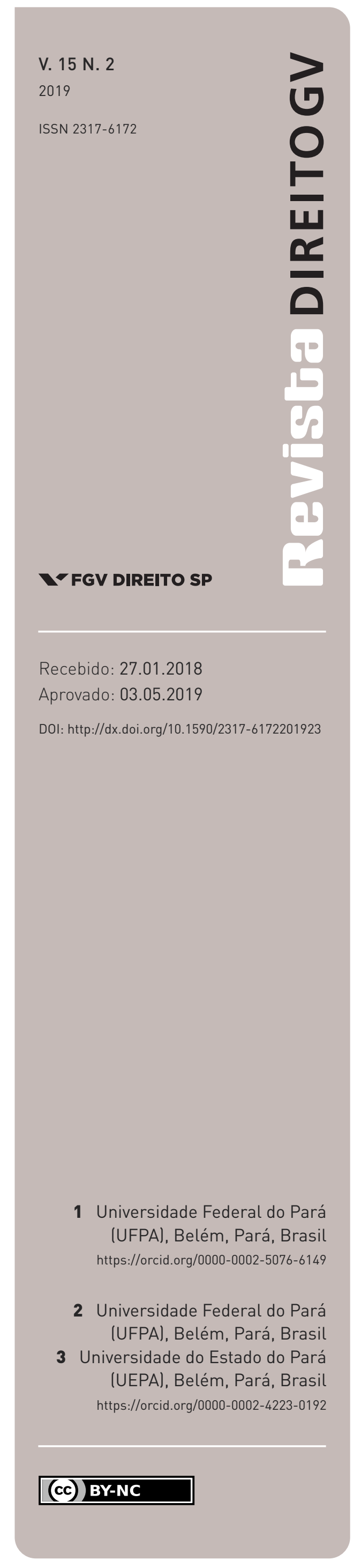

\section{Associação interna como forma de integração dos presídios às redes externas do tráfico: a percepção dos agentes territoriais da segurança pública no estado do Pará}

INTERNAL ASSOCIATION AS A FORM OF INTEGRATION OF THE PRISONS TO THE TRAFFIC EXTERNAL NETWORKS: THE PERCEPTION OF THE TERRITORIAL AGENTS OF THE PUBLIC SECURITY IN THE STATE OF PARÁ

\author{
Roberto Magno Reis Netto ${ }^{1}$ e Clay Anderson Nunes Chagas ${ }^{2,3}$
}

\section{Resumo}

Este artigo busca compreender a estratégia de estabelecimento e manutenção de redes ou relações entre os agentes sintagmáticos internos ao cárcere como forma de integração dos presídios às redes territoriais externas do tráfico de drogas, a partir da percepção de agentes territoriais da segurança pública no estado do Pará. Pautado em um método hermenêutico e dialético, e sob uma abordagem qualitativa e quantitativa, o presente estudo se valeu da técnica de coleta de dados por entrevistas direcionadas a agentes territoriais da segurança pública no estado do Pará, seguida de uma análise do conteúdo das falas. Essa análise dos dados confirmou a existência da estratégia considerada, bem como suas possíveis peculiaridades locais (relativas à influência das transferências e à inadvertida junção de presos no cárcere). Igualmente, restaram identificados aspectos práticos sobre o processo de cooptação de internos e a centralidade das lideranças, bem como elementos relativos à economia interna das facções da atividade do tráfico de drogas.

\section{Palavras-chave}

Tráfico de drogas; cárcere; redes e relação entre internos; agentes territoriais da segurança pública.

\begin{abstract}
This article sought to understand the strategy of establishing and maintaining networks or relationships between the syntagmatic agents internal to the jail as a way of integrating the prisons to the external territorial networks of drug trafficking, from the perception of territorial agents of public security in the State of Pará, Brazil. Based on a hermeneutic and dialectical method, and under a qualitative and quantitative approach, it used the technique of data collection by interviews directed to territorial security agents in the State of Pará, followed by an analysis of the content of the answers. The analysis of the data confirmed the existence of the related strategy, as well as its possible local peculiarities /concerning the influence of transfers and inadvertent joining of prisoners in prison). Likewise, were identified practical aspects regarding the process of cooptation of inmates and centrality of the leaderships, as well as elements related to the internal economy of the factions of the drug trafficking activity.
\end{abstract}

\section{Keywords}

Drug trafficking; jail; networks and relationship between interns; territorial agents of public safety. 


\section{INTRODUÇÃO}

O presente artigo decorre de pesquisa desenvolvida no Programa de Pós-Graduação em Segurança Pública da Universidade Federal do Pará (UFPA). Em um primeiro momento, a referida pesquisa firmou uma ampla revisão literária, como primeira aproximação de seu problema principal: as estratégias e os mediatos utilizados pelos agentes territoriais do tráfico de drogas para integração dos presídios às redes territoriais externas da atividade (REIS NETTO e CHAGAS, 2018). A categorização, realizada à luz da teoria base de Claude Raffestin (1993), apontou como estratégias o estabelecimento / manutenção de redes e relações entre os agentes sintagmáticos internos ao cárcere, o estabelecimento / manutenção de relações e cooptação de agentes do sistema penitenciário, a utilização de mediatos para comunicação a partir do cárcere, o estabelecimento /manutenção de redes e relações junto a agentes sintagmáticos públicos ou privados externos ao cárcere, o estabelecimento de redes comerciais internas do tráfico de drogas e, por fim, o enfrentamento direto de agentes sintagmáticos e atingimento de símbolos vinculados ao poder público (REIS NETTO e CHAGAS, 2018).

Contudo, a despeito da importância da atividade teórica realizada, ainda assim, vislumbrou-se que uma contribuição mais coerente aos problemas enfrentados pela segurança pública (como a insuficiência das ações meramente repressivas no enfrentamento do tráfico de drogas [RODRIGUES, 2004] e o surgimento das facções, que detêm nos entorpecentes sua principal fonte lucrativa [DIAS, 2013; AMORIM, 2011 e 2015]) dependia, ainda, de uma aproximação empírica, justamente para a compreensão das peculiaridades locais do fenômeno.

Diante dessa constatação, o presente trabalho adotou como objetivo analisar a estratégia de associação interna, como modo de integrar os presídios às redes territoriais externas do tráfico de drogas, a partir de percepções de agentes territoriais da segurança pública do estado do Pará. Pretendeu-se, assim, compreender o fenômeno e suas peculiaridades no âmbito estadual, revelando informações potencialmente importantes à ciência e aos componentes da própria segurança pública.

\section{REFERENCIAL TEÓRICO}

Em primeiro lugar, deve-se ressaltar que a análise das manifestações sociais do crime na América Latina, no século XXI, depende da compreensão das transformações vividas pelas comunidades ocidentais alinhadas ao bloco liberal no século XX. Como ressaltou David Garland (2008), a crise do capitalismo, registrada ao fim da década de 1970, em decorrência, sobretudo, da crise mundial do petróleo, resultou em um processo de reversão do modelo sociopolítico do Welfare State, bem como na mudança do programa fordista-fabril de produção.

As transformações, em verdade, representaram uma busca progressiva pela superação de entraves ao modelo de produção, que, obviamente, também significavam óbices ao lucro dos investidores (GARLAND, 2008). Iniciou-se, assim, um movimento político pela redução do papel estatal na instância previdenciária e assistencial (permitindo a reversão de recursos para financiamento da economia), bem como pela assunção de medidas de flexibilização 
dos meios de produção e das normas trabalhistas, sob o argumento de que o sucesso das empresas giraria a máquina de mercado e, com isso, permitiria a reversão de benefícios em prol da população.

Ao mesmo tempo, intensificou-se o estímulo ao consumo desenfreado, em um processo em que se exigia cada vez mais das classes trabalhadoras (como produtora e consumidora). Assim, a dedicação às longas jornadas de trabalho, os bombardeios sinópticos destinados ao consumo em massa e a ampliação dos índices de desemprego e subemprego (decorrentes da fragilidade das relações de trabalho) resultaram no enfraquecimento de instâncias sociais como a família e a comunidade, intensificando a construção de relações sob o primado da individualidade (GARLAND, 2008; BAUMAN, 2001). Ampliou-se, com isso, o já existente contexto de desigualdade social, ao passo que a criminalidade passou a registrar significativo recrudescimento (GARLAND, 2008), em especial em relação a crimes que garantem (até hoje) uma relativa participação no excludente mercado de consumo (notadamente, os crimes contra o patrimônio e as modalidades de tráfico de drogas).

Como resposta jurídico-penal, e ignorando toda a construção criminológica havida nas décadas anteriores, uma série de pressões políticas e econômicas conduziu os estados à retomada de posturas criminológicas clássicas, pautadas na repressão e na rotulação de inimigos sociais (WACQUANT, 2015). Associou-se, cada vez mais, categorias como raça, local de moradia e nível social à ideia de criminalidade, ao passo que o sistema judiciário e o cárcere passaram a representar um dos principais instrumentos de gestão de classes indesejadas, excluídas do mercado formal e da sociedade de consumo. Igualmente, registrou-se um aumento das taxas de encarceramento, sobretudo de jovens pobres, negros, de baixa escolaridade e sem emprego formal. Assim, ao deixarem de investir em programas sociais de prevenção de riscos (inclusive contra o ingresso no mundo da criminalidade), os estados passaram a financiar a repressão e o sustento de um inflacionado sistema penitenciário.

Esse modelo, ressalte-se, foi amplamente exportado a outros países integrantes do bloco liberal (por opção ou determinação - como no caso de tratados assinados sob ameaça de embargos econômicos) e acabou por registrar resultados mais graves ainda em países menos desenvolvidos (como o Brasil e demais países da América Latina), haja vista o menor grau de investimentos sociais e o alto nível de disparidade entre classes historicamente registrado.

Nesse contexto, é de se afirmar que a política de tratamento criminal do tráfico de drogas representou um papel muito importante a esse modelo de gestão da pobreza pelo aprisionamento - Estado Penal (GARLAND, 2008; WACQUANT, 2015). A Guerra às Drogas, além de constituir uma política exportada com facilidade pela via das pressões político-econômicas desempenhadas no âmbito internacional, sobretudo pelos Estados Unidos, representa, ainda, uma política que tem justificado, em muitos países, ações seletivas sobre as parcelas pobres da população (D'ELIA FILHO, 2014), marcadas por um forte subjetivismo prático (CARVALHO, 2016) e que ocultariam interesses econômicos relevantes (VALOIS, 2017). No Brasil, a construção legal das espécies do crime de tráfico de drogas não foi diferente. 
Assim, para contemplar uma visão aprofundada a respeito do tráfico, enquanto fenômeno social de significativa complexidade (DIAS, 2013; ARAÚlJO, 2012), impõe-se a superação de sua análise sob um conceito estritamente jurídico-legal (RODRIGUES, 2004; CARVALHO, 2016), justamente em função da vinculação dessa concepção com as parcialidades oriundas da política de Guerra às Drogas e sua interessada postura de concentração de patentes do uso de substâncias ditas entorpecentes nas mãos de grupos econômicos específicos (notadamente, a indústria farmacêutica) (VALOIS, 2017), além de seu emprego como justificativa para repressão de contingentes populacionais (RODRIGUES, 2004).

Em verdade, a legislação (artigos 33, 34, 37 e 38, da Lei n. 11.3434/2006 - Lei Antidrogas) apenas conglobou a proibição de uma cadeia de atividades que revelavam um ciclo da produção e da comercialização de produtos (drogas). Nesse sentido, mostrou-se mais coerente compreender a ação do tráfico como algo análogo a uma empresa (CHAGAS, 2014). Constatou-se, assim, que os agentes do tráfico buscariam a dominação e o controle de territórios com importância comercial (conforme critérios de oferta/demanda), em contraposição aos interesses de outros agentes, como o Estado, valendo-se de diversas estratégias (ou seja, conjuntos de ações coordenadas a um fim) e mediatos (meios utilizados para implementação das estratégias) para atingimento de finalidades planejadas conforme suas necessidades - ou seja, seus planos sintagmáticos (planos de poder) (RAFFESTIN, 1993). Desse modo, os traficantes se denotariam como agentes sintagmáticos (ou seja, que agem conforme interesses planejados), que se estabeleceriam em certo espaço, gerando o surgimento de territórios (decorrentes dos conflitos de poder firmados no espaço) que superariam a lógica meramente zonal, preponderante na óptica estatal, caracterizando-se, também, como territórios-rede (ligados por diversos pontos - nós - no espaço) e como territórios simbólicos (que vinculariam seus agentes por intermédio de uma afetividade ao espaço) (RAFFESTIN, 1993; HAESBAERT, 2014).

Seguindo a lógica capitalista global, o tráfico de drogas se organizou, de um lado, em oligopólios de atuação transnacional, pouco visíveis pelos órgãos de segurança, e, de outro, em fileiras de atravessadores e revendedores, estes em geral atingidos pelas ações repressivas atualmente empregadas como agenda pública de enfrentamento do problema (RODRIGUES, 2004; D’ELIA FILHO, 2014). Essa repressão, por sua vez, impôs (como referido antes) uma verdadeira política de aprisionamento seletivo de parcelas mais vulneráveis da população (que viram no tráfico a oportunidade de inserção em um mercado substancialmente excludente) (D’ELIA FILHO, 2014) e, com isso, uma desterritorialização precária (HAESBAERT, 2014) de grandes contingentes populacionais para o cárcere.

Como preceituou Gabriel Ignacio Anitua (2015), o discurso criminológico segregador decorrente das posturas relatadas desvirtuou o próprio discurso legal de reinserção social e conclamou a prisão como o isolamento puro e simples de delinquentes. E, diante da ausência de políticas efetivamente ressocializadoras, esse aprisionamento, com o tempo, apenas desafiou os agentes encarcerados à efetivação de estratégias de resistência à política estatal preponderante, 
o que, no Brasil, resultou no advento de faç̧ões (organizações criminosas) que encontraram no tráfico de drogas sua principal atividade econômica (DIAS, 2013; AMORIM, 2011 e 2015).

Como assinalou Orlando Zaccone D’Elia Filho (2014), a política punitivista apenas reforçou a ideia de exclusão social de pessoas já excluídas, em pouco, atingindo a real parcela lucrativa do empreendimento. Essa situação, conforme Camila Nunes Dias (2013), apenas incentivou os rotulados como criminosos à busca de novas formas de associação e, assim, de permanência no lucrativo comércio das drogas - e, consequentemente, na sociedade de consumo, mesmo dentro das prisões. O tráfico de drogas, desse modo, se impôs além das grades, justamente em razão da eficiência das estratégias manejadas por seus agentes territoriais sintagmáticos na vinculação dos presídios às redes territoriais externas, bem como em decorrência da falência das políticas estatais de compreensão e enfrentamento do problema (DIAS, 2013).

Como mencionado, no âmbito macro desta pesquisa, firmou-se uma revisão da literatura envolvendo a relação entre tráfico e cárcere, a qual resultou na inferência de seis espécies de estratégias de integração das prisões às redes territoriais externas do tráfico, classificadas e categorizadas a partir das ações relatadas por diversos autores (REIS NETTO, 2018; REIS NETTO e CHAGAS, 2018). Por sua vez, no teor do presente estudo, realizou-se um esforço de aprofundamento em torno do problema, voltado à análise de uma daquelas estratégias, no contexto territorial contemporâneo do estado do Pará: o estabelecimento e a manutenção de redes e relações entre os agentes sintagmáticos internos ao cárcere.

Essa estratégia representaria um conjunto de ações pelas quais, em um movimento em prol da construção (e, posteriormente, da manutenção) de redes de tráfico, os agentes da atividade promoveriam a tessitura de redes territoriais (ou seja, relações de poder no espaço, instituídas por nós e pontos em diferentes locais [RAFFESTIN, 1993]) no interior das cadeias, propiciando condições para o eficiente manejo das demais estratégias (que se intercruzam e se aplicam de maneira simultânea [DIAS, 2013]) para interligação do cárcere ao mundo externo. O surgimento dessa prática foi atribuído ao referido processo de desterritorialização precária (HAESBAERT, 2014) ao cárcere, que, desacompanhado de medidas ressocializadoras, teria gerado uma proximidade entre os agentes encarcerados, de modo que estes passaram a interligar suas redes externas (não desfeitas com o simples aprisionamento) e representar, uns em relação aos outros, verdadeiros trunfos de poder (RAFFESTIN, 1993) na ampliação de suas relações comerciais do tráfico (DIAS, 2013; AMORIM, 2011 e 2015; SAVIANO, 2014; TEIXEIRA, 2015), continuando uma prática já existente no âmbito externo.

Essa associação, aliás, foi apontada como principal fator originário de grandes facções, como o Comando Vermelho (CV) (no Rio de Janeiro, no final da década de 1970) e o Primeiro Comando da Capital (PCC) (na década de 1990, em São Paulo), além de outras surgidas em razão das vantagens decorrentes da associação entre agentes territoriais, ou, simplesmente, como modo de rivalizar (pelo controle de territórios) com os grupos em ascensão (DIAS, 2013; AMORIM, 2011 e 2015). Por sua vez, diversos autores destacaram que essa estratégia foi facilitada pelo uso indiscriminado do instituto das transferências de presos entre 
estabelecimentos prisionais, que não só teria permitido a construção de novas redes entre agentes do tráfico encarcerados, como, sobretudo, teria ocasionado a disseminação da ideologia (de paz entre os ladrões) das facções por diversos presídios do país (DIAS, 2013; AMORIM, 2011 e 2015; GODOY e TORRES, 2017; TEIXEIRA, 2015; MARQUES, 2014; SAVIANO, 2014; LOURENÇO e ALMEIDA, 2013; FERRO, 2012; VARELLA, 2017).

Inclusive, a criação de regimes mais duros de encarceramento, notadamente, o Regime Disciplinar Diferenciado (RDD), apenas teria reforçado imagens simbólicas de poder em torno de lideranças, sem promover de modo efetivo uma quebra de suas relações de territorialidade (PIEDADE e CARVALHO, 2015; DIAS, 2013; MALLART, 2014). Com isso, ainda que sob razões não apontadas de maneira clara na literatura, propiciou-se a consolidação de funções de liderança nas mãos de agentes encarcerados (SAVIANO, 2014 e 2015; TALESE, 2011; FORGIONE, 2011; SALAZAR, 2014; DIAS, 2013; AMORIM, 2011 e 2015; LOURENÇO e ALMEIDA, 2013), no sentido de atribuir-lhes poderes de organização de hierarquias e atividades internas e de tomada de decisões sobre planos, julgamentos (os debates) e ações territoriais externas (OLIVEIRA e COSTA, 2012; AMORIM, 2011 e 2015; DIAS, 2011 e 2013; SILVA, 2013; LOURENÇO e ALMEIDA, 2013; CAPITANI, 2012; TEIXEIRA, 2015; MARQUES, 2014; ABREU, 2017; VARELLA, 2017; BARCELLOS, 2015; SAVIANO, 2014; MALVASI, 2012; GODOY e TORRES, 2017).

Consolidou-se um controle da violência nas mãos das organizações criminosas, justamente como forma de instituir uma ordem interna fundamental ao exercício de atividades inerentes ao domínio territorial (DIAS, 2013; VARELLA, 2017; DIAS, ALVAREZ e SALLA, 2013; LOURENÇO e ALMEIDA, 2013; MARQUES, 2014; SAVIANO, 2014), interessante não só às facções (que precisam do contexto de calma para realização do mercado de drogas), como, igualmente, ao sistema prisional e ao Estado (que seriam coniventes com esta - politicamente interessante - paz velada [DIAS, 2013; AMORIM, 2011 e 2015]).

Essas lideranças passaram a organizar, portanto, o comportamento (proceder) dos presos, estabelecendo códigos de conduta, apreendendo demandas dos internos, consolidando regras cogentes de convivência, instituindo julgamentos de transgressões (os debates) e mecanismos de controle do comércio interno de drogas (QUEIROZ, 2016; MALLART, 2014; DIAS, 2011 e 2013; DIAS e SALLA, 2013; ANDRADE, 2015; MALVASI, 2012; SAVIANO, 2014; AMORIM, 2011 e 2015; LOURENÇO e ALMEIDA, 2013; SILVA, 2013; TEIXEIRA, 2015; MARQUES, 2014; VARELLA, 2017; BARCELLOS, 2015). Além disso, as facções também teriam instituído uma rede assistencial, por meio da qual formaram caixinhas financiadas por seus membros para garantir benefícios aos internos associados (contratação de advogados, compra de benefícios e bens, financiamento de resgates e fugas, etc.) e não associados (cessão de cestas básicas e gêneros básicos de sobrevivência) nos presídios (AMORIM, 2011 e 2015; DIAS, 2013; VARELLA, 2017; DIAS, ALVAREZ e SALLA, 2013), cuja finalidade, além de assegurar o silêncio (DIAS, 2013; AMORIM, 2011 e 2015; ABREU, 2017), seria, notadamente, fidelizar os beneficiários às organizações (DIAS e SALLA, 2013). 
Igualmente, passou-se a utilizar a droga como instrumento de poder, que garantiria a mobilização da população carcerária para efetivação dos planos das organizações do cárcere, por intermédio não só de uma rede de comércio interno, mas, sobretudo, pela possibilidade de interdição do uso e do comércio de substâncias conforme os interesses daquelas, viabilizado pelo controle que a prática associativa ocasionou concretamente (AMORIM, 2011 e 2015; DIAS, 2013 e 2014; ANDRADE, 2015; ALMEIDA et al., 2013; MALVASI, 2012; FIGUEIRÓ, 2014; GODOY; TORRES, 2017).

Diante dessas relevantes menções literárias, o presente estudo buscou compreender se esta seria, de fato, a realidade vivenciada pelo estado do Pará na atualidade. Para tanto, realizou-se uma análise do fenômeno, de natureza qualitativa, a partir das percepções de agentes vinculados à segurança pública, que tomou como ponto de partida os registros literários previamente colhidos (REIS NETTO e CHAGAS, 2018). Mostrou-se necessária a adoção de um conjunto de técnicas metodológicas específicas e cuidados éticos pertinentes, explicados na seção a seguir.

\section{MÉTOdo e TÉCNICAS DE PESQUISA}

Em primeiro lugar, como substrato epistemológico, o estudo adotou o método hermenêutico e dialético (STEIN, 1983; HABERMAS, 1987; MINAYO, 2002), consistente em uma opção científica que toma a linguagem como base do conhecimento sensível (aspecto hermenêutico), não a considerando, entretanto, um dado bruto e definitivo. Esse método parte da premissa de que o conhecimento (e, portanto, a linguagem) é influenciável pelo contexto social, econômico, político e histórico em que se inserem os sujeitos envolvidos em determinado estudo.

A comunicação, desta feita, surgiria por meio de uma linguagem sistemicamente perturbada (HABERMAS, 1987) pelas relações que permeiam seus emissores, devendo ser analisada, assim, como algo potencialmente alienável (movimento dialético). Assim, para desvelar as influências decorrentes das relações de poder inerentes aos agentes comunicativos, o método propugna pela(o): a) a consideração dos aspectos históricos dos emissores das informações; b) o respeito à linguagem de cada pesquisado, por mais simples que ela seja; e c) a busca pelo real sentido da informação emitida por cada indivíduo. Após esses cuidados, é prudente a realização, ainda, de triangulações internas (entre os emissores) e externas, tanto com base em uma teoria fundante de um estudo quanto em face da literatura produzida.

Dessa maneira, o método adequou-se com perfeição à proposta, justamente por ter permitido, em um momento anterior, a inferência de informações decorrentes de obras com diferentes objetos de estudo (REIS NETTO e CHAGAS, 2018), porém, sempre tocantes à relação tráfico e cárcere, e, neste estudo, por permitir a análise da visão de um grupo específico de agentes territoriais locais (agentes territoriais da segurança pública), desvelando eventuais distorções decorrentes de seu papel e de sua situação dentro das relações de poder. 
Por conseguinte, adotou-se uma abordagem qualitativa (focada no conteúdo do discurso dos entrevistados). Como técnica de pesquisa, utilizou-se a coleta de dados por intermédio de entrevistas, que, no dizer de Wendy Olsen (2015), importa em uma interação entre o pesquisador e os sujeitos detentores de informações, para apreensão de dados oriundos de saberes e percepções.

Para tanto, restou elaborado um protocolo de entrevista (YIN, 2016), com 32 questões semiestruturadas, confeccionadas a partir de constatações literárias prévias e controladas pela teoria (FLICK, 2009), em torno das seis espécies de estratégias mencionadas (cujas repostas foram classificadas, neste trabalho, somente em relação à estratégia de estabelecimento $e$ manutenção de redes ou relações entre os agentes sintagmáticos internos ao cárcere, conforme objetivo eleito). As demais estratégias deram origem a outros artigos específicos, em razão dos limites de extensão desta espécie de trabalho. É de se reafirmar que as estratégias em estudo são manejadas, como constatou Dias (2013), de maneira intercruzada, pelo que, embora o protocolo tenha delimitado perguntas relativas somente à estratégia apresentada, observou-se, quando de sua aplicação, a ocorrência de menções sobre ela ao longo de toda a fala dos entrevistados. Assim, para a exposição de resultados, recorreu-se ao trabalho da técnica de análise de conteúdo (BARDIN, 2011), com o objetivo de categorização das falas e dos dados.

A escolha dos entrevistados, por conseguinte, deu-se em razão de indicações decorrentes da literatura inicialmente consultada: foram escolhidos sujeitos apontados como ocupantes de funções em órgãos e atividades que, por sua natureza (de enfrentamento ao problema ou assessoria), teriam contato efetivo com os agentes territoriais do tráfico e suas respectivas estratégias, sendo, assim, detentores de conhecimentos interessantes ao estudo.

Ainda, conforme recomendado por RobertYin (2016), houve uma aproximação cuidadosa junto ao campo de pesquisa (facilitada pela condição de docentes da área de inteligência e segurança pública, ostentada pelos pesquisadores) para verificação das formas de acesso, obstruções a serem removidas e, finalmente, se, de fato, os entrevistados seriam detentores das informações buscadas, após o que, por fim, restaram definidos os sujeitos da entrevista.

Foram entrevistados, desse modo: a) na Polícia Civil do Estado do Pará: o diretor do Núcleo de Inteligência Policial e o diretor da Delegacia de Narcóticos, ambos delegados no exercício da função no momento da entrevista; b) na Polícia Militar do Estado do Pará: o comandante do Batalhão de Polícia Penitenciária, oficial em exercício da função no momento da entrevista; c) na Superintendência do Sistema Penitenciário do Estado do Pará: o diretor da Assessoria de Segurança Institucional, oficial da Polícia Militar no exercício da função no momento da entrevista; d) no Ministério Público do Estado do Pará: o diretor do Grupo de Atuação Especial contra o Crime Organizado, promotor de Justiça no exercício da função no momento da entrevista; e) na Ordem dos Advogados do Brasil - Seção Pará: o vice-presidente da Comissão de Segurança Pública, advogado eleito para a função, em exercício no momento da entrevista; f) na Polícia Federal: o superintendente da Polícia Federal no Pará, delegado federal no exercício da função no momento da entrevista. 
As entrevistas foram realizadas entre o fim de abril de 2017 e o início de janeiro de 2018 (em razão de afastamentos e questões emergenciais ocorridas em algumas das instituições) na sede dos órgãos indicados ou em locais escolhidos pelos entrevistados, em salas reservadas e em horários previamente agendados, justamente para manutenção de uma situação de tranquilidade e controle de interferências, gerando, assim, um clima amistoso que permitiu manifestações comprometidas com a proposta apresentada.

Como protocolo ético: a) foram selecionados somente sujeitos que exerciam funções diretivas, ou seja, representantes legais autorizados a falar em nome dos órgãos e entidades, destinatários finais de informações importantes, dispensando-se, na maioria dos casos, a necessidade de autorizações orgânicas (providenciadas quando solicitado); b) as entrevistas foram precedidas da leitura, explicação e subscrição de Termo de Consentimento Livre e Esclarecido (TCLE), expositivo da pesquisa, objetivos, vinculação institucional, interesses e riscos e desconfortos, bem como da total garantia do sigilo de identidades e dados. Como a identificação dos entrevistados, ainda assim, não seria dificultosa, garantiu-se que os resultados não fariam menção às instituições, não apresentariam unanimidades em relação às opiniões, como forma de respeito ao sigilo das manifestações, e comportariam somente trechos das falas, como cuidado adicional tendente à não identificação da origem de um indivíduo. Os entrevistados foram genericamente identificados pelas siglas E1, E2, E3, E4, E5, E6 e E7.

As respostas foram transcritas, fragmentadas em enunciados específicos e sujeitas a um procedimento de análise de conteúdo (BARDIN, 2011). Foram, assim, organizadas em uma tabela de dupla entrada e submetidas a um primeiro processo de categorização. Em seguida, como propugnado pelo método, cada enunciado foi sujeito a uma triangulação (MINAYO, 2002) com a literatura consultada de antemão (REIS NETTO e CHAGAS, 2018) e com a teoria territorial base do estudo (RAFFESTIN, 1993), justamente no sentido de desvelar perturbações sistêmicas decorrentes da posição funcional dos entrevistados, que, na qualidade de integrantes do Poder Público, decerto detêm uma fala de caráter institucional, porém, cujo contato real com o fenômeno em análise se apresentou como uma importante fonte primária digna de aprofundamento e estudo.

\section{Resultados E Discussões}

\section{I ESTRATÉgia de ASSOCiação INTERna}

Em primeiro lugar, constatou-se uma convergência entre a fala dos entrevistados e a hipótese destacada por alguns autores (DIAS, 2013; AMORIM, 2011 e 2015; SAVIANO, 2014; TEIXEIRA, 2015) de que a proximidade entre os agentes territoriais no cárcere, de fato, facilitaria o surgimento de associações e redes territoriais entre eles. Mencionou-se que problemas de alocação de presos no cárcere, como a junção de internos provisórios e definitivos, a reunião de líderes de tráfico de certas áreas em semelhantes presídios ou, ainda, a junção de presos por 
crimes de natureza diferenciada, sem maiores critérios ou cuidados, propiciariam a troca de conhecimentos e experiências entre eles, de modo a permitir a conexão das redes preexistentes ou, ainda, a conjugação de outras atividades (roubos e furtos) à atividade originária de determinada organização (tráfico).

Referiu-se, por exemplo que: "[...] começa a juntar pessoas com expertises diferentes, cabeças e experiências diferentes, dentro de um mesmo local, e é óbvio que [...], o tempo todo, vão trocar informações e tentar, ainda dentro do cárcere, obter lucro” (E1). "O cara que entrou por roubo já sai sabendo sequestrar, [...] traficar, conseguir o entorpecente e onde conseguir, de que forma ele vai traficar, ele acaba aumentando o leque dele pernicioso dentro do sistema" (E4). "Você coloca junto e isso faz com que pessoas que nem se conheciam possam se conhecer: você trafica no (nome de bairro), eu trafico na (nome de bairro), vamos fazer um intercâmbio?!" (E6). Igualmente, a permissão de proximidade entre membros de mesmas facções foi apontada como critério que potencializaria a comunicação entre os agentes territoriais, facilitando a integração entre suas redes internas e externas: "É porque, assim, não existe um critério. Por exemplo, qual seria o ideal? Que membros de uma mesma facção não ficassem no mesmo bloco, mas não existe esse critério" (E4).

Do mesmo modo, confirmou-se a afirmação de alguns autores consultados (DIAS, 2013; VARELLA, 2017; DIAS, ALVAREZ e SALLA, 2013; LOURENÇO e ALMEIDA, 2013; MARQUES, 2014; SAVIANO, 2014) de que, compreendendo que o tráfico de drogas seria a atividade mais lucrativa à disposição (o que não significa um abandono das demais espécies criminais, ressalte-se), os criminosos teriam constatado a necessidade de se associar internamente, sobretudo, para manutenção de uma paz em seus pavilhões, sob o objetivo de reduzir as intervenções das forças de segurança no local, em uma política de gestão territorial da violência. Nesse sentido, afirmou-se: “Qual é a forma mais fácil de ter lucro no cárcere? É comandar o tráfico de drogas aqui fora. É mais fácil se aliar do que brigar entre si” (E1). "Dentro do cárcere, eles vão se aliar, tentar estabelecer o mínimo de controle, [...] depois passam do controle pra divisão territorial, de forma que não crie nem um conflito lá dentro, [...] o tempo vai passando e eles vão se estruturando" (E7). "Quem controla dentro do cárcere quem vai ficar na cela de quem, homicídios, controle de tráfico, tudo, é a facção criminosa, porque eles sabem que, se eles se desorganizarem lá dentro, os conflitos podem emergir" (E3). "Uma das prioridades das facções dentro dos presídios é controlar o presídio, [...] isso auxilia o controle deles dentro do cárcere, como fora, nas áreas de influência” (E5).

Esse controle, assim, estaria diretamente ligado à manutenção da tranquilidade necessária para o exercício do comércio de drogas e outras atividades ilícitas, afastando fiscalizações: "Eles se organizam lá justamente pra dominar esse comércio. Basicamente, [...] não querem benefícios de um, de outro. Eles querem é facilitar o comércio, o tráfico de drogas [...]”, afinal, “[...] quanto mais controle tiverem lá, menos a polícia vai fazer a incomodação deles lá” (E2).

Emblemática, nesse sentido, foi a menção relativa ao presídio de regime semiaberto da Região Metropolitana de Belém, a Colônia Penitenciária Agrícola de Santa Izabel (CPASI). 
Na CPASI, o controle de todas as atividades pertenceria às lideranças do crime (ante a impossibilidade de enfrentamento de criminosos por parte do reduzido quantitativo de agentes prisionais): "Ele é um presídio comandado pelos presos, não tem muro. Se ele quiser sair a qualquer hora, ele pode sair. Não tem policial lá, não tem guarita e o agente penitenciário também tá cercado. São 140 presos, então ali ninguém vai segurar eles” (E3).

Quanto à repercussão das transferências de presos entre diferentes casas penais, como elemento influente à associação interna, a fala dos entrevistados guardou relação com evidências de algumas obras (DIAS, 2013; AMORIM, 2011 e 2015; GODOY e TORRES, 2017; TEIXEIRA, 2015; MARQUES, 2014; SAVIANO, 2014; LOURENÇO e ALMEIDA, 2013; FERRO, 2012 ; VARELLA, 2017), ao apontar que, embora a medida até possa trazer resultados imediatos, a longo prazo, acaba-se por originar e/ ou fortalecer redes entre criminosos. Nesse sentido, afirmou-se que: "A transferência, em si, ela não é, como eu falei, uma má ideia. A ideia de você transferir preso é você retirar aquela pessoa daquele local, em que ela tem um comando reconhecido" (E6), porém, "quando ela sair desse presídio, ela tem contatos em outros lugares do Brasil, não só onde ela tinha antes, que era em Belém, por exemplo” (E6). "Então eles chegam em um presídio federal e eles têm contato com membros de facções criminosas já estruturadas, que apresentam pra eles uma doutrina e uma forma de se reorganizar" (E1). "Se ficar transferindo toda hora, eles vão ficar tendo um intercâmbio de informações, aí vai ficar mais fácil pra eles e vão ficar mais fortalecidos" (E3).

Metaforicamente, comparou-se a transferência a presídios federais a uma pós-graduação no mundo do crime: "O presídio normal é a graduação, os outros são as pós, porque os presídios federais, a partir do momento [em] que eles agregam os presos mais perigosos do Brasil, de alguns locais, você acaba criando, quer queira, quer não, o vínculo entre eles” (E6). Este, inclusive, teria sido o embrião de facções criminosas no estado do Pará, conforme se observou das falas: "No Pará foi assim. Influência externa. Teve transferências de presos do sistema penitenciário estadual pro presídio federal, então eles chegam em um presídio federal e têm contato com membros de facções criminosas já estruturadas" (E1); "Sempre na origem de uma facção aqui no Estado tá uma situação de um preso que foi transferido pro presídio federal, tanto do Comando Vermelho quanto [do] Primeiro Comando da Capital” (E5).

Em segundo lugar, também se destacou que a transferência de presos (seja líderes, seja faccionados) da capital para o interior, mais uma vez, acabaria por ocasionar os mesmos problemas destacados: "A rede territorial é aumentada, principalmente, com as transferências do interior pra capital. Quando eles retornam pra cidade deles, eles já voltam com uma organização criminosa, com vários outros contatos" (E5). Isso também contribui, certamente, para a reputada construção de imagens simbólicas de liderança sobre o transferido apontada em algumas obras (PIEDADE e CARVALHO, 2015; DIAS, 2013; MALLART, 2014).

\subsection{Centralização de lideranças e recrutamento de faccionados}

No que toca ao fenômeno de centralização de lideranças das facções no contexto do cárcere, encontrada 
em apontamentos de diversos autores (SAVIANO, 2014 e 2015; TALESE, 2011; FORGIONE, 2011; SALAZAR, 2014; DIAS, 2013; AMORIM, 2011 e 2015; LOURENÇO e ALMEIDA, 2013), constatou-se que a cadeia, de fato, representaria um local seguro para a elaboração e a implementação dos planos sintagmáticos de poder das organizações criminosas. A título de exemplo, transcreve-se o trecho da fala de dois dos entrevistados em que se destacou: "A gente pensa que os líderes dessas facções foram presos, sendo que, muitas vezes, se deixaram prender. Fora, eles correriam risco de vida, teriam que ter segurança pra salvaguardar sua integridade. Dentro, quem passa [a] fazer esse trabalho é [o] Estado" (E4); "Muitas vezes, a liderança não quer nem sair daqui, [...] prefere ficar aqui do que ficar solto. Ele tá liderando mais aqui do que lá fora. Fica mais fácil liderar daqui de dentro" (E3).

No mesmo sentido, foi afirmado que, de fato, caberia aos líderes encarcerados a definição de planos sintagmáticos externos das organizações criminosas, como decisões sobre o controle do tráfico, a defesa e a expansão territorial: “As pessoas que estão lá estão determinando diretamente às que [es]tão fora a exercer o tráfico de drogas, tanto comprando e vendendo como organizando a venda de drogas em outros países" (E2). "O mais frequente dentro das investigações é que essas áreas territoriais sejam comandadas por um expoente do crime que hoje está preso dentro de um cárcere, dentro do sistema penitenciário estadual” (E1).

Além disso, apontou-se o exercício, pelos líderes, de um controle sobre a massa carcerária, definindo um conjunto de regras relativas ao comportamento (proceder), bem como utilizando essa população como um trunfo de poder, definindo momentos em que ela se rebelaria ou realizaria protestos no cárcere, ou fazendo que detentos falassem em nome do líder (mantendo-o oculto e, assim, protegido): "Lá é um quartel-general de líderes, ou seja, lá eles montam suas hierarquias, tem as torres, tem os conselheiros, [...] seguem uma regra lá” (E2). "A figura do próprio crime organizado, às vezes, [es]tá atrás de pessoas escolhidas pra poder ser o porta-voz. A verdadeira liderança do crime organizado não apresenta alterações" (E7). "Se [o] líder daquela unidade prisional é mais violento, a cadeia tende a ser mais violenta. Se ele é mais racional, a cadeia tende a ser mais racional” (E4). "As lideranças aqui das cadeias, na verdade, controlam muita coisa que não [es]tá tendo aqui, como motim, rebelião, quebra-quebra, porque a liderança lá dentro [es]tá se segurando, não quer confusão” (E3).

Destacou-se, também, que líderes ocupariam posições especiais nos presídios (como a função de faxineiro), justamente porque elas lhes permitiriam maior circulação e o consequente exercício tranquilo de suas atribuições em grande parte do território interno: "Em troca deixo ele livre, tiro da segurança máxima e deixo ele livre, coloco ele como faxineiro dentro da cadeia porque o faxineiro é a pessoa que transita entre todas as celas” (E1).

Por conseguinte, no mesmo sentido relatado por diversos autores (DIAS, 2013; AMORIM, 2011 e 2015; GODOY e TORRES, 2017; TEIXEIRA, 2015; MARQUES, 2014; SAVIANO, 2014; LOURENÇO e ALMEIDA, 2013; FERRO, 2012; VARELLA, 2017), destacou-se que o recrutamento por parte das facções, de fato, seria permeado por diversos elementos simbólicos e por uma ideologia de paz entre os ladrões e enfrentamento ao sistema: "Essa ideologia em 
comum é o enfrentamento ao sistema, ou seja, a partir do momento [em] que a questão da tortura, da agressão, da violação de direitos dos presos passou a ser uma sistemática dentro do sistema carcerário, houve um contraponto por parte deles" (E5). "Eles vendem essa ideologia, e alguns rituais são feitos para ser criado esse espírito de corpo. Não é qualquer um que entra, você tem que passar por uma triagem, você tem que ter um padrinho" (E1).

No entanto, essa ideologia, em verdade, estaria voltada somente à criação de imagens de convencimento, registrando um contraponto interessante aos textos referidos anteriormente, que colocaram o simbolismo como um ponto central do processo de recrutamento. Nesse sentido, mencionou-se: "Então todos eles veem como se a organização criminosa estivesse brigando, não pelo comércio de tráfico de drogas, não pela arrecadação de dinheiro, mas pela ideologia central, pela paz, justiça e liberdade” (E1). "São apenas figuras que são utilizadas pelas organizações, que são pregadas para os demais membros, para os soldados, mas que, na verdade, não são utilizadas, não são seguidas à risca” (E4). Essa percepção dos agentes de segurança é bastante relevante. Segundo se colheu das falas, o intento de lucro sempre estaria acima de qualquer ideal ou causa comum entre os criminosos, ao passo que os simbolismos seriam elementos com uma função de sedução (sobretudo, dos menos experientes no mundo do crime) para obtenção de faccionados.

Um dos entrevistados, inclusive, afirmou que, em sua atividade profissional, já presenciou membros de facções reclamando do comportamento de faccionados paraenses, uma vez que haveria uma grande dificuldade de fidelização de criminosos que mudariam de facções facilmente, conforme a melhor oferta: "Tem uns que até reclamam, porque, assim, eles trocam de facção no momento [em] que o auxílio não tá chegando. Por exemplo, se morre um da facção e o líder não vai cobrar, ele já parte para o outro lado lá” (E2). Embora seja uma imagem que possa espelhar uma afirmação no sentido de desmoralizar as facções (decorrente da posição pública dos entrevistados), ainda assim trata-se de dado que guarda possível verdade diante do forte caráter econômico inerente ao tráfico, apontado no referencial deste estudo.

Além disso, informou-se que o elemento sobrevivência estaria fortemente vinculado ao processo de recrutamento: "É uma relação de sobrevivência em que quem tem algo a oferecer sempre vai encontrar, em razão da própria miséria, das transformações atrozes que o sistema tem, uma oferta pra ser aceita” (E7). “A primeira coisa que eles oferecem é 'me dá tanto por mês que eu te garanto proteção dentro do sistema'. O cara tá com medo, nunca cometeu nem um crime, nem nada, a primeira vez que ele caiu no sistema ele fica com medo e acaba cedendo" (E5). Nesses termos, os neófitos do sistema prisional, pelo contexto de violência e extorsão, sentiriam-se compelidos a escolher um lado e se faccionar, como modo de preservar sua vida.

Dessas informações, duas hipóteses podem ser levantadas: a) a primeira é a de que o sistema ideológico de recrutamento talvez ainda não tenha sido eficientemente implantado no Pará, ao contrário do que se observaria no Sudeste, funcionando muito mais a partir do medo do que pela promessa de benefícios ou de paz; b) a segunda é a de que, em um processo insinuado por 
autores como Dias (2013) e Amorim (2011 e 2015), embora existente, a ritualística sirva para ocultar, de fato, os interesses econômicos do tráfico de drogas, se valendo das imagens para alijar as massas do verdadeiro lucro da atividade.

Em seguida, alguns entrevistados também destacaram, em relação ao processo de recrutamento, que seria justamente o descumprimento aos direitos previstos na Lei de Execução Penal (Lei n. 7.210/1984), em especial quanto às garantias de ressocialização, que criariam o ambiente apropriado para a adesão de agentes territoriais ao tráfico e, como consequência, o surgimento de organizações hierarquizadas: "Onde não existe a figura do Estado, ou onde o Estado não se faz presente de modo forte, ele por si só abre espaço para que haja um assistencialismo, assistencialismo este intramuros da cadeia e extramuros da cadeia” (E7).

Essa ausência estatal, por sua vez, foi apontada pelos entrevistados como determinante ao sucesso da fidelização de internos, por meio da concessão de medidas clientelistas aos faccionados e suas famílias, conforme também foi indicado pela literatura (ABREU, 2017; AMORIM, 2011 e 2015; DIAS, 2013; VARELLA, 2017; DIAS, ALVAREZ e SALLA, 2013): "Quando eles entram na cadeia, sempre chega algum representante da facção e diz: 'Você tem advogado? Nós vamos te auxiliar no pagamento de advogado, nós vamos tentar auxílio monetário para que sua esposa traga alimentos pra cá pra dentro ou ajude sua família lá fora"” (E1). "Se você é transferido pra um presídio federal, a facção paga as passagens e até estadia pra sua esposa ir do estado de origem até próximo do presídio federal" (E6). "É uma forma de prender o interno. Quando o preso vai pra regime federal, se ele faz parte de uma fação, a família toda dele é levada, uma casa é alugada, advogado é pago, a família fica junto” (E4).

Entretanto, um importante contraponto foi registrado em relação à questão da ausência de garantia de direitos e ressocialização. Colocou-se que, em alguns casos, seria impossível atingir a ressocialização de detentos, diante de sua total subversão ao crime, embora não se negue que o ambiente também não auxiliaria nesse processo: "O que eu posso te falar é: não adianta ressocializar quem não quer ser ressocializado, entendeu? E, principalmente, ressocializar em um ambiente inóspito. Como?” (E3). A fala parece comungar com os postulados criminológicos advindos das sociedades de consumo massivo do século XXI, nos quais os Estados, sobretudo os alinhados ao bloco neoliberal, passaram a adotar posturas cada vez menos comprometidas com ideais de ressocialização, típicas do período do Welfare State, retomando políticas repressivas típicas das criminologias clássicas (ANITUA, 2015).

Em todo caso, como nem mesmo a criminologia crítica conseguiu demonstrar o sucesso da ressocialização no combate ao crime, de fato, é natural o surgimento de opiniões divergentes sobre o assunto, até mesmo pela natural subjetividade humana (que não segue regras matemáticas para fins ressocializantes ou de autorreflexão sobre o crime e o castigo).

\subsection{Aspectos econômicos da ASSOCiAçÃo E do COMÉrcio DE DROGAS}

Em outro ponto, verificou-se a existência das caixinhas, como destacado por certos autores (AMORIM, 2011 e 2015; DIAS, 2013 e 2014; ANDRADE, 2015; ALMEIDA et al., 2013; 
MALVASI, 2012; FIGUEIRÓ, 2014; GODOY e TORRES, 2017). Esses fundos ilegais seriam mantidos pelas contribuições dos afiliados, bem como pela realização de ações como rifas e sorteios para levantamento de dinheiro voltado ao atendimento das medidas clientelistas mencionadas anteriormente e para o financiamento do tráfico: "Um outro ramo dentro das facções criminosas, às vezes, gera rifas, você recolhe dinheiro dos internos e sorteia prêmio pra eles e os prêmios são desde bicicletas, armas, drogas, etc.” (E1).

Conforme alguns entrevistados destacaram, a droga seria utilizada para a aquisição de favores e bens, assim como modo de indução de consumidores viciados ao cumprimento de ordens determinadas pelos agentes territoriais do tráfico (assumindo a condição de veículo de degradação ou escravidão entre internos) e, em uma perspectiva mais grave, como forma de controle da cadeia (que seria acalmada ou agitada de acordo com a quantidade de droga disponibilizada à massa): "Hoje, o que é controlado pelas facções é o tráfico de drogas com relação à maconha. Se eles veem que a massa carcerária está agitada, eles liberam mais maconha, ou então eles liberam menos para forçar um integrante a entrar na facção e obedecer" (E1). "Ela é uma forma de favor; por exemplo, como eu te falei, preso que não tem nada, mas ele quer usar a droga dele, vai pagar com outra coisa, ele vai pagar quando sair daqui, com roubo, ou vai trabalhar com o tráfico" (E3). "A droga é utilizada como instrumento de poder dentro do cárcere privado" (E7).

No entanto, uma peculiaridade foi encontrada. Ao contrário do que a literatura referenciada apontou, em alguns presídios do Pará, a mensalidade seria cobrada, também, de presos não faccionados, revelando uma subversão do discurso de afiliação para garantia da paz entre os ladrões: "Então, por exemplo, no presídio de (nome) lá em (cidade), tem a mensalidade. Cada preso que não é faccionado tem que pagar pro chefe da cadeia. O que é essa mensalidade? É a proteção dele” (E3). Reforça-se a ideia, já mencionada anteriormente, de que o medo ainda seria o principal elemento de adesão às facções no Pará.

\section{CONSIDERAÇÕES FINAIS}

Como consideração final, deve-se afirmar que as percepções dos agentes territoriais da segurança pública, de fato, confirmaram a associação interna como estratégia relevante à integração dos presídios às redes territoriais externas do tráfico de drogas, a qual, no contexto territorial do estudo, seria facilitada pela inadvertida alocação de presos (provisórios ou não, bem como indiciados por diferentes delitos) e pelo uso do instituto da transferência entre casas penais (entre estados ou entre diferentes cidades do Pará).

Do mesmo modo, foram identificados importantes aspectos relativos ao processo de recrutamento de internos pelas facções, bem como foram levantadas hipóteses sobre o papel dos rituais e simbolismos vinculados a esse processo. Além disso, foram reveladas possíveis causas da centralidade das lideranças entre os presos encarcerados e aquelas relativas ao emprego da violência e do medo no processo de associação. 
Ademais, foram destacados aspectos econômicos da associação (notadamente, a formação da caixinha e suas finalidades) e questões que revelaram o uso da droga como importante instrumento de poder nas relações do cárcere. Em suma, da análise do fenômeno aqui discutido, foram levantados dados a respeito da associação local, relevantes tanto à ciência quanto à administração penitenciária e à segurança pública do estado do Pará.

\section{REFERÊNCIAS}

ABREU, Allan de. Cocaína: a rota caipira: o narcotráfico no principal corredor de drogas do Brasil. Rio de Janeiro: Record, 2017.

ALMEIDA, Marco Antônio Betinne de; GUTIERREZ, Gustavo Luis; CHICARELI, Semiramis Costa; CIDRO, Débora. Lazer e o presídio: aspectos de um paradoxo. São Paulo: Each, 2013.

AMORIM, Carlos. Comando Vermelho: a história do crime organizado. Rio de Janeiro: BestBolso, 2011.

AMORIM, Carlos. CV - PCC: a irmandade do crime. 13. ed. Rio de Janeiro: Record, 2015.

ANDRADE, Eliakim Lucena de. Sem derramamento de sangue: religião e violência na prisão. Cadernos de Campo: Revista de Ciências Sociais, n. 19, p. 155-176, 2015.

ANITUA, Gabriel Ignacio. História dos pensamentos criminológicos. Rio de Janeiro: Revan, 2015.

ARAÚJJ, Tarso. Almanaque das drogas. São Paulo: Leya, 2012.

BARCELlOS, Caco. Abusado: o dono do morro Santa Marta. 26. ed. Rio de Janeiro: Record, 2015.

BARDIN, Laurence. Análise de conteúdo. São Paulo: Edições 70, 2011.

BAUMAN, Zygmunt. Modernidade líquida. Rio de Janeiro: Zahar, 2001.

CAPITANI, Rodrigo. O meio ambiente prisional brasileiro e a saúde do preso: um estudo no Presídio Estadual de Bento Gonçalves. Dissertação (Mestrado em Direito) - Universidade de Caxias do Sul, Caixas do Sul, 2012.

CARVALHO, Salo de. A política criminal de drogas no Brasil: estudo criminológico e dogmático da Lei 11.343/06. 8. ed. São Paulo: Saraiva, 2016. 
CHAGAS, Clay Anderson Nunes. Geografia, segurança pública e a cartografia dos homicídios na região metropolitana de Belém. Boletim Amazônico de Geografia, v.1, n. 1, p. 186-204, 2014.

D’ELIA FILHO, Orlando Zaccone. Acionistas do nada: quem são os traficantes de drogas. Rio de Janeiro: Revan, 2014.

DIAS, Camila Nunes. Estado e PCC em meio às tramas do poder arbitrário nas prisões. Tempo Social, v. 23, n. 2, p. 213-233, 2011.

DIAS, Camila Nunes. PCC: hegemonia nas prisões e monopólio da violência. São Paulo: Saraiva, 2013.

DIAS, Camila Nunes. Disciplina, controle social e punição: o entrecruzamento das redes de poder no espaço prisional. Revista Brasileira de Ciências Sociais, v. 29, n. 85, p. 113-127, 2014.

DIAS, Camila Nunes; ALVAREZ, Marcos César; SALLA, Fernando. Das comissões de solidariedade ao Primeiro Comando da Capital em São Paulo. Tempo Social, v. 25, n. 1, p. 61-82, 2013.

DIAS, Camila Nunes; SALLA, Fernando. Organized crime in Brazilian prisons: the example of the PCC. International Journal of Criminology and Sociology, v. 2, n. 2, p. 397-408, 2013.

FERRO, Ana Luiza Almeida. Uma proposta legislativa para o enfrentamento da criminalidade organizada. De Jure, Revista Jurídica do Ministério Público do Estado de Minas Gerais, v. 11, n. 19, p. 85-111, 2012.

FIGUEIRÓ, Rafael Albuquerque. Apontamentos sobre a prisão na pós-modernidade: o caso brasileiro. In: Anais doVI Congreso Internacional de Investigación y Práctica Profesional en Psicología, XXI, Jornadas de Investigación, X Encuentro de Investigadores en Psicología del Mercosur. 2014. Buenos Aires: Facultad de Psicología, Universidad de Buenos Aires, 2014.

FLICK, Uwe. Introdução à pesquisa qualitativa. 3. ed. Porto Alegre: Artmed, 2009.

FORGIONE, Francesco. Mafia export: como a 'Ndrangheta, a Cosa Nostra e a Camorra colonizaram o mundo. Rio de Janeiro: Bertrand Brasil, 2011.

GARLAND, David. A cultura do controle: crime e ordem social na sociedade contemporânea. Rio de Janeiro: Revan, 2008.

GODOY, Gabriel; TORRES, Bolivar. Baladas proibidas: a história do rei do ecstasy. Rio de Janeiro: Record, 2017. 
HABERMAS, Jürgen. Dialética e hermenêutica: para a crítica da hermenêutica de Gadamer. Porto Alegre: LP\&M, 1987.

HAESBAERT, Rogério. Viver no limite: território e multi/transterritorialidade em tempos de insegurança e contenção. Rio de Janeiro: Bertrand Brasil, 2014.

LOURENÇO, Luiz Claudio; ALMEIDA, Odilza Lines de. Quem mantém a ordem, quem cria desordem. Tempo Social, v. 25, n. 1, p. 37-59, 2013.

MALLART, Fábio. Cadeias dominadas: a fundação CASA, suas dinâmicas e as trajetórias de jovens internos. São Paulo: Terceiro Nome, 2014.

MALVASI, Paulo Artur. Interfaces da vida loka: um estudo sobre jovens, tráfico de drogas e violência em São Paulo. Tese (Doutorado em Saúde Pública) - Faculdade de Saúde Pública, Universidade de São Paulo, São Paulo, 2012.

MARQUES, Adalton. Crime e proceder: um experimento antropológico. São Paulo: Alameda, 2014.

MINAYO, Maria Cecília de Souza. Hermenêutica-dialética como caminho do pensamento social. In: MINAYO, Maria Cecília de Souza. Caminhos do pensamento: epistemologia e método. Rio de Janeiro: Fiocruz, 2002.

OLIVEIRA, Giovanni França; COSTA, Gustavo Villela Lima. A cidade e os informantes: inserção etnográfica nos pontos de venda de drogas da cidade de Corumbá/Brasil. Revista de Ciências Sociais da Universidade Federal de Mato Grosso do Sul, v. 11, n. 6, p. 02-24, 2012.

OLSEN, Wendy. Coleta de dados: debates e métodos fundamentais em pesquisa social. Porto Alegre: Penso, 2015.

PIEDADE, Fernando Oliveira; CARVALHO, Maria Luciene. Sistema prisional de Pedrinhas em São Luís do Maranhão: presente conturbado e futuro incerto. In: Anais do XII Seminário Internacional de Demandas Sociais e Políticas Públicas na Sociedade Contemporânea, VIII Mostra de Trabalhos Jurídicos Científicos. Santa Cruz do Sul: Universidade de Santa Cruz do Sul, 2015.

QUEIROZ, Nana. Presos que menstruam: a brutal vida das mulheres - tratadas como homens - nas prisões brasileiras. 5. ed. Rio de Janeiro: Record, 2016.

RAFFESTIN, Claude. Por uma geografia do poder. São Paulo: Ática, 1993. 
REIS NETTO, Roberto Magno. Além das grades: a integração dos presídios às redes territoriais externas do tráfico de drogas. Dissertação (Mestrado em Segurança Pública) - Instituto de Filosofia e Ciências Humanas, Universidade Federal do Pará, Belém, 2018.

REIS NETTO, Roberto Magno; CHAGAS, Clay Anderson Nunes. Estratégias e mediatos utilizados pelo tráfico de drogas para integração dos presídios às redes territoriais externas: uma revisão da literatura. Revista Opinião Jurídica, v. 16, n. 23, p. 110-139, 2018.

RODRIGUES, Thiago. Política e drogas nas Américas. São Paulo: Educ/Fapesp, 2004.

SALAZAR, Alonso. Pablo Escobar: ascensão e queda do grande traficante de drogas. São Paulo: Planeta, 2014.

SAVIANO, Roberto. Zero, zero, zero. São Paulo: Companhia das Letras, 2014.

SAVIANO, Roberto. Gomorra: a história real de um jornalista infiltrado na violenta máfia napolitana. 10. ed. Rio de Janeiro: Bertrand Brasil, 2015.

SILVA, Leandro Damasceno e. A lei n. 9.034/95 e as organizações criminosas brasileiras, THEMIS, v. 11 , n. 11, p. 267-280, 2013.

STEIN, Ernildo. Dialética e hermenêutica: uma controvérsia sobre o método em Filosofia. Síntese, v.1, n. 29 , p. 21-48, 1983.

TALESE, Gay. Honra teu pai. São Paulo: Companhia das Letras, 2011.

TEIXEIRA, Alessandra. Construir a delinquência, articular a criminalidade: um estudo sobre a gestão dos ilegalismos na cidade de São Paulo. Tese (Doutorado em Sociologia) - Faculdade de Filosofia, Letras e Ciências Humanas, Universidade de São Paulo, São Paulo, 2015.

VALOIS, Luís Carlos. O direito penal da guerra às drogas. 2. ed. Belo Horizonte: D’Plácido, 2017.

VARELLA, Drauzio. Carcereiros. São Paulo: Companhia das Letras, 2012.

VARELLA, Drauzio. Estação Carandiru. 2. ed. São Paulo: Companhia das Letras, 2015.

VARELLA, Drauzio. Prisioneiras. São Paulo: Companhia das Letras, 2017.

WACQUANT, Loïc. Punir os pobres: a nova gestão da miséria nos Estados Unidos [a onda punitiva]. 3. ed. Rio de Janeiro: Revan, 2015. 
YIN, Robert. Pesquisa qualitativa: do início ao fim. Porto Alegre: Penso, 2016.

\section{COMO CITAR ESTE ARTIGO:}

REIS NETTO, Roberto Magno; CHAGAS, Clay Anderson Nunes. Associação interna como forma de integração dos presídios às redes externas do tráfico: a percepção dos agentes territoriais da segurança pública no estado do Pará. Revista Direito GV, v. 15, n. 2, 2019 , e1923. doi: http://dx.doi.org/10.1590/ 2317-6172201923.

\section{Roberto Magno Reis Netto}

Doutorando em Geografia pela Universidade Federal do

PARÁ (UFPA), COM ÊNFASE EM DINÂMICAS TERRITORIAIS NA Amazônia (linha: Geografia e Segurança Pública). Mestre em Segurança Pública (UfPA). Especialista em Atividade de INTELIGÊNCIA E GESTÃO DO CONHECIMENTO (ESMAC/PA), EM

DocÊnCIA No Ensino SUPERIOR (UGF/DF) E EM DiREITO Processual Civil (UgF/DF). Bacharel em Direito (UFPA). Oficial de Justiça Avaliador (TJPA). Professor (Faculdade da Amazônia e Escola Superior Madre Celeste) e Pesquisador (Membro do Laboratório de Pesquisa em Geografia da ViolÊNCIA E dO CRIME LABGEOVCRIM/UEPA - dO GRUPO dE PESquisa MÉTOdos E Diagnósticos em Segurança Pública - UFPA - e do InStiTUto Científico dA AmazÔNiA - ÉRgane).

bob_reis_ufpalayahoo.com.br

\section{Clay Anderson Nunes Chagas}

DOUTOR EM DESENVOLVIMENTO SOCIOAMBIENTAL PELA UNIVERSIDADE

Federal do Pará (UFPA). Mestre em Desenvolvimento SustentáVEL do TRÓPICO ÚMIDO (UFPA). BACHAREL EM GEOGRAFIA

(UFPA). Vice-Reitor da Universidade do Estado do ParÁ

(UEPA). Professor do Programa de Pós-Graduação em

Segurança Pública da UfPa e dos programas de Pós- Graduação em Geografia da UEPA e da UFPA. Professor-Colaborador da Universidade de Cabo Verde (Uni-CV) no Programa de Pós-Graduação em Segurança Pública.

Associado ao Fórum Brasileiro de Segurança Pública (FBSP). Membro do Instituto Histórico Geográfico do PARÁ (IHGP). LídER DO LABORATÓRIO DE PESQUISA EM GEOGRAFIA DA VIOLÊNCIA E DO CRIME (LABGEOVCRIM/UEPA).

claychagas@ufpa.br 